\title{
CFD Modelling of a Stepped Spillway with Various Step Layouts
}

\author{
Shicheng Li, ${ }^{1}$ Qiulin Li $\mathbb{D}^{2}$ and James Yang $\mathbb{D}^{1,3}$ \\ ${ }^{1}$ Department of Civil and Architectural Engineering, Royal Institute of Technology (KTH), Stockholm 10044, Sweden \\ ${ }^{2}$ Southwest Science Research Institute of Water Transport Engineering, Chongqing Jiaotong University, Chongqing 400016, China \\ ${ }^{3}$ Vattenfall AB, RઐD Hydraulic Laboratory, Älvkarleby 81426, Sweden
}

Correspondence should be addressed to Qiulin Li; leeqlin@sina.com

Received 9 September 2019; Accepted 30 October 2019; Published 28 November 2019

Academic Editor: Luca Chiapponi

Copyright (c) 2019 Shicheng Li et al. This is an open access article distributed under the Creative Commons Attribution License, which permits unrestricted use, distribution, and reproduction in any medium, provided the original work is properly cited.

\begin{abstract}
A traditional stepped spillway is prone to cavitation risks. To improve its hydraulic behaviors, distorted step faces and pool weirs are devised. By numerical modelling, comparative studies are conducted to look into the flow features. The pressures on step surfaces of the unconventional layouts exhibit 3D distributions. Pool weirs are essential in increasing both the min. and max. pressure loads. Pressures on the downstream bed show a unique pattern for V-and inverted V-shaped models, with the extreme pressures at the sidewalls for the former and at the central plane for the latter. Symmetrical secondary flows are formed in V-and inverted V-shaped cases with different patterns. Distributions of turbulent kinetic energy suggest differences in flow motions in all cases. Furthermore, the relative energy loss of flat setups is $\sim 5.4 \%$ lower than that of the pooled ones with the same step face angle; inverting the face angle does not give rise to noticeable change. The results provide reference for relevant projects.
\end{abstract}

\section{Introduction}

With the advances in roller compacted concrete (RCC) techniques, stepped spillways have gained popularity with a wide range of applications including hydropower [1-3]. As unique roughness elements, steps play an important role in improving energy dissipation and aeration efficiency [4-6]. As a result, construction costs are considerably low owing to the reduced dimensions of the downstream energy dissipation facility $[7,8]$. Effective air entrainment contributes to reduction in cavitation damages [9-11]. Despite a large number of research projects, the complexity of the flows in stepped spillways makes the hydraulic design fairly difficult.

Felder and Chanson [12] studied air concentration and energy dissipation of a stepped spillway with nonuniform step heights. Pfister and Hager [13] examined the self-aeration characteristics of flows in stepped spillways. Researchers [14-16] also investigated air-water mixture flows and turbulence properties. In addition, novel designs are also implemented to increase the hydraulic performances of traditional stepped spillways. For instance, Felder [6]; Zare and Doering [17]; and Kökpinar [18] looked into the aeration and flow resistance in stepped spillways with sills and baffles. Experiments by Zare and Doering [19] suggested higher energy dissipation by rounding the step edges. Inclining steps upwards is effective in lowering the outlet velocity and increasing energy loss [20]. 3D flow motions are produced by changing the step face angle, leading to higher head loss and aeration [21].

Most of the studies of novel designs focused on the energy dissipation and air entrainment; examinations of step configurations are relatively limited. This paper illustrates, through 3D numerical simulations, the flow features of several step layouts. The aim is to reveal the effects of geometrical layouts of steps on pressure loads and flow structures, which would contribute to better understanding of their hydraulic characteristics and to effective engineering measures in design of stepped spillways.

\section{Numerical Simulation}

Felder and Chanson [22] carried out a series of experiments to study the hydraulic properties of the skimming flow over a stepped spillway, providing references for similar projects. Therefore, based on their model (shown in Figure 1), several modifications are made to investigate the effects of step 


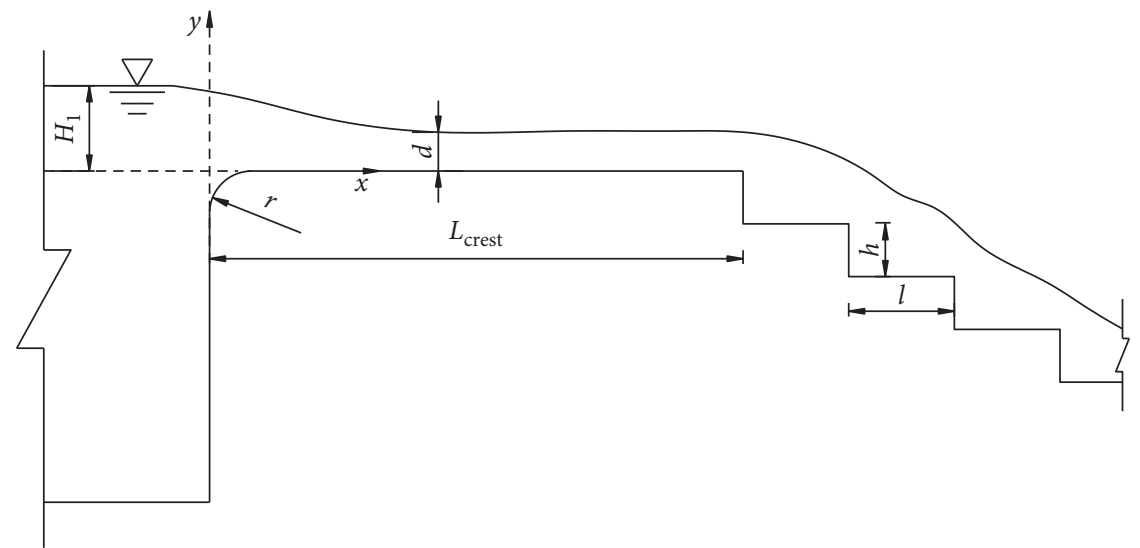

Figure 1: Sketch of the physical model setup.

layout on the flow characteristics. The spillway has 10 identical steps with step height $h=0.10 \mathrm{~m}$ and step length $l=0.20 \mathrm{~m}$. The water is supplied from an upstream tank. A board-crested weir, with a length of $L_{\text {crest }}=1.01 \mathrm{~m}$ and a rounded corner $(r=0.08)$, conveys water the examined steps. The width of the spillway channel is $w=0.52 \mathrm{~m}$. In this paper, spillway layouts are redesigned through changes in the step face angle $(\theta)$ and additions of pool weir, as displayed in Figure 2.

2.1. Numerical Model. Performing CFD simulations is an effective tool to study complex flow problems [23-26]. Previous CFD studies [21, 27-29] reported the capability of the $k-\varepsilon$ model in reproduction of the major hydraulic characteristics of the flows over stepped spillways. Therefore, in the current study, this turbulence model by Launder and Spalding [30] is used to look into the spillway flow features with different step layouts. The governing equations of the $k-\varepsilon$ model are as follows:

$k$ equation:

$$
\begin{aligned}
& \frac{\partial(\rho k)}{\partial t}+\frac{\partial}{\partial x_{i}}\left(\rho u_{i} k\right)=\frac{\partial}{\partial x_{i}}\left[\left(\mu+\frac{\mu_{t}}{\sigma_{k}}\right) \frac{\partial k}{\partial x_{i}}\right]+G_{k}-\rho \varepsilon \\
& \varepsilon \text { equation: } \\
& \frac{\partial(\rho \varepsilon)}{\partial t}+\frac{\partial\left(\rho u_{i} \varepsilon\right)}{\partial x_{i}}=\frac{\partial}{\partial x_{i}}\left[\left(\mu+\frac{\mu_{t}}{\sigma_{\varepsilon}}\right) \frac{\partial \varepsilon}{\partial x_{i}}\right]+C_{1 \varepsilon} \frac{\varepsilon}{k} G-C_{2 \varepsilon} \rho \frac{\varepsilon^{2}}{k}
\end{aligned}
$$

where

$$
\begin{aligned}
\mu_{t} & =\rho C_{\mu} \frac{k^{2}}{\varepsilon} \\
G_{k} & =\mu_{t}\left(\frac{\partial u_{i}}{\partial x_{j}}+\frac{\partial u_{j}}{\partial x_{i}}\right) \frac{\partial u_{i}}{\partial x_{j}}
\end{aligned}
$$

in which $\rho=$ flow density, $u_{i}$ and $u_{j}=$ velocity component, $t=$ time and $\mu=$ dynamic viscosity. The empirical constants include $C_{\mu}=0.09, \sigma_{k}=1.0, \sigma_{\varepsilon}=1.3, C_{1 \varepsilon}=1.44$, and $C_{2 \varepsilon}=1.92$.
The volume of fluid (VOF) technique is employed to track the air-water interface. So, $\rho$ and $\mu$ are obtained from

$$
\begin{aligned}
& \rho=\alpha_{\mathrm{w}} \rho_{\mathrm{w}}+\left(1-\alpha_{\mathrm{w}}\right) \rho_{\mathrm{a}}, \\
& \mu=\alpha_{\mathrm{w}} \mu_{\mathrm{w}}+\left(1-\alpha_{\mathrm{w}}\right) \mu_{\mathrm{a}},
\end{aligned}
$$

where $\alpha_{\mathrm{w}}=$ volume fraction of water, $\rho_{\mathrm{w}}=$ water density, $\rho_{\mathrm{a}}=$ air density, $\mu_{\mathrm{w}}=$ water viscosity, and $\mu_{\mathrm{a}}=$ air viscosity.

2.2. Boundary Conditions. Figure 3 shows the boundary conditions and local mesh pattern (for the VS layout). The upstream inlet includes two parts: the upper part as pressure inlet and the lower part as velocity inlet. The downstream boundary is set as pressure outlet; the top surface is given as pressure inlet. Moreover, the unmentioned boundaries, such as the channel bottom and sidewalls, are treated as solid wall. The inflow rate ranges from 0.063 to $0.113 \mathrm{~m}^{3} / \mathrm{s}$.

2.3. Model Calibration. The sensitivity of numerical solutions is checked using grid convergence index (GCI) [3134]. The method, commonly used to estimate the uncertainty of CFD modelling, is expressed by indexes GCI and S:

$$
\begin{aligned}
\mathrm{GCI}= & \frac{1.25\left|\left(\phi_{1}-\phi_{2}\right) / \phi_{1}\right|}{\left(h_{2}-h_{1}\right)^{S}-1}, \\
S= & \frac{1}{\ln \left(h_{2} / h_{1}\right)}|\ln | \frac{\phi_{3}-\phi_{2}}{\phi_{2}-\phi_{1}} \mid \\
& +\left|\ln \left(\frac{\left(h_{2} / h_{1}\right)^{S}-\operatorname{sgn}\left[\left(\phi_{3}-\phi_{2}\right) /\left(\phi_{2}-\phi_{1}\right)\right]}{\left(h_{3} / h_{2}\right)^{S}-\operatorname{sgn}\left[\left(\phi_{3}-\phi_{2}\right) /\left(\phi_{2}-\phi_{1}\right)\right]}\right)\right|,
\end{aligned}
$$

where $\phi_{i}(i=1,2,3)=$ selected numerical results and $h_{i}(i=1,2,3)=$ grid size. Three grids with $41.5,76.9$, and 92.8 million cells are generated to evaluate grid independence.

Figure 4 shows the numerical solutions with error bars using GCI, where $V_{x}=$ velocity in the $x$ direction, $V_{\mathrm{c}}=\sqrt{g \times d_{\mathrm{c}}}=$ critical flow velocity, $d_{\mathrm{c}}=$ critical flow depth, and $P=$ flow pressure. It is obvious that the 


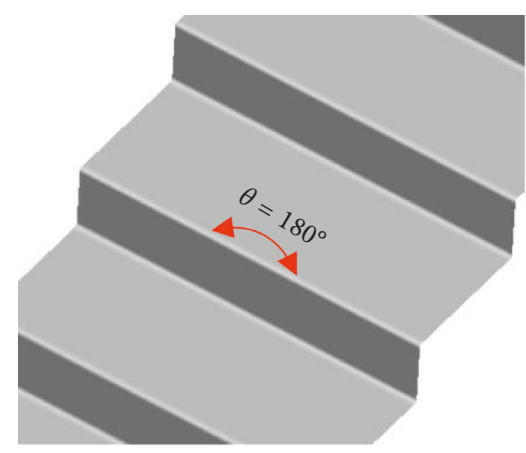

(a)

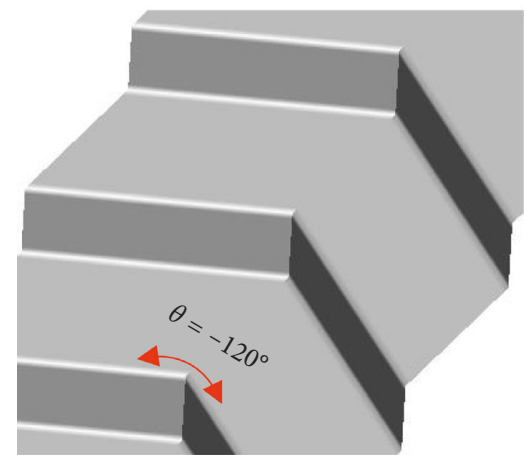

(d)

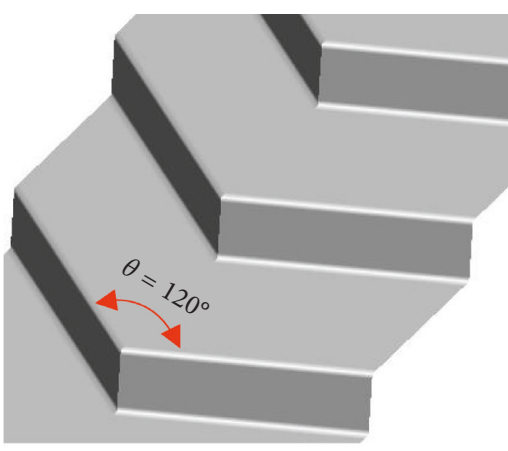

(b)

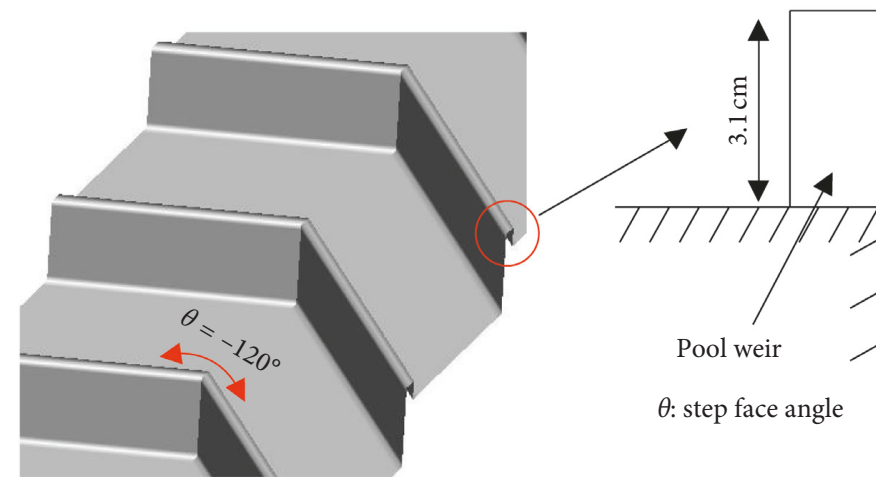

(e)

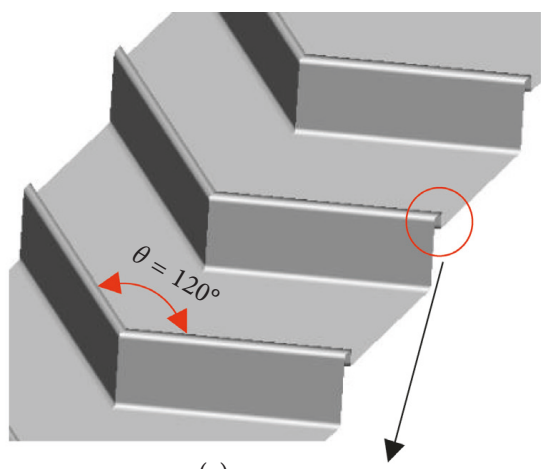

(c)

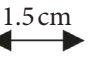

FIGURE 2: Spillway configurations: (a) traditional stepped spillway (TS); (b) V-shaped stepped spillway (VS); (c) pooled V-shaped stepped spillway (PVS); (d) inverted V-shaped stepped spillway (IVS); and (e) pooled inverted V-shaped stepped spillway (PIVS).

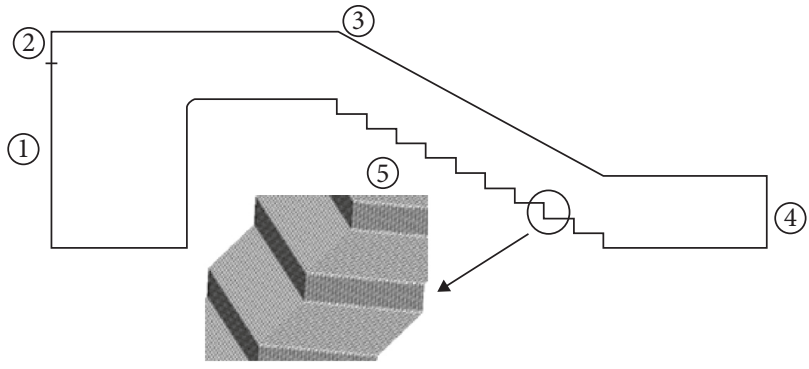
(1) Velocity inlet
(4) Pressure outlet
(2) Pressure inlet
(5) Walls
(3) Pressure inlet

Figure 3: Computational domain with local enlargement and boundary conditions.

uncertainty of the results is small at most positions. The max. uncertainties of the normalized pressure and flow velocity are $8.4 \%$ and $6.6 \%$, respectively. In view of this and affordable CPU time, the selection of the 76.9 million cells is reasonable.

With the grid independence checked, the numerical results are also compared with the experimental data from Felder and Chanson [22]. Figures 5(a)-5(c) present comparisons of the free surface, velocity profile, and pressure distribution. As seen, the discrepancies between the computational data and laboratory work are small. The max. relative errors for the water surface, velocity, and pressure are $2.8 \%, 8.8 \%$, and $4.6 \%$, respectively. The good agreement between the results shows that the numerical model produces, with accuracy, the key hydraulic features of the stepped spillway.

\section{Results and Analysis}

Due to the transverse motion of the water flow, the pressures on the spillway bottom vary greatly and exhibit a typical 3D pattern. Let $z$ be transverse axis with $z=0$ at the central plane of the spillway channel. To show the pressure distribution pattern, three planes are selected (Figure 6): $z / w=0$ (axial plane), $z / w=0.25$, and $z / w=0.5$ (sidewall), where $\rho=$ density of water and $g=$ gravitational acceleration.

3.1. Pressures on Horizontal Step Surface. For the TS layout, the pressures exhibit S-shaped variations, whose patterns remain almost unchanged in the transverse direction. The VS and IVS pressure fluctuations show an opposite trend in the spanwise direction. For the former, a large change is found at $z / w=0.5$ and a little variation at $z / w=0$. As for PVS, the pressure fluctuations increase from $z / w=0$ to 0.5 , 


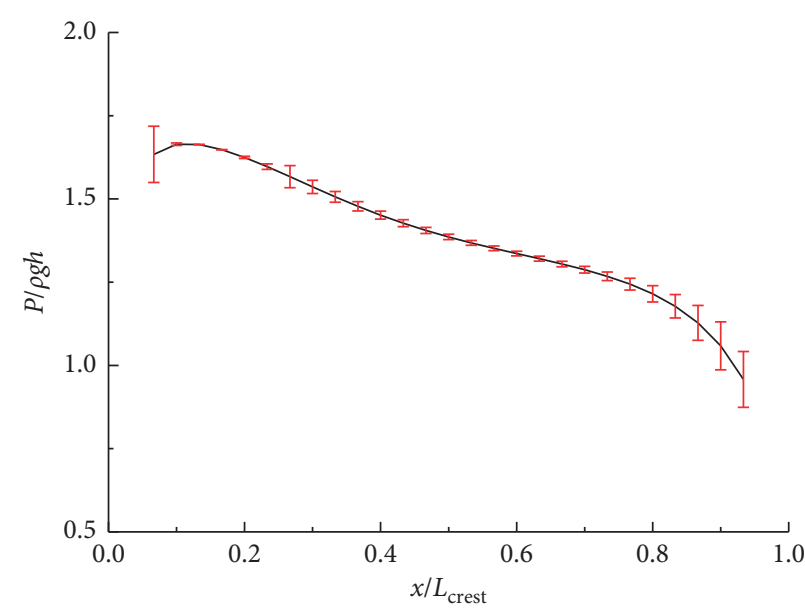

(a)

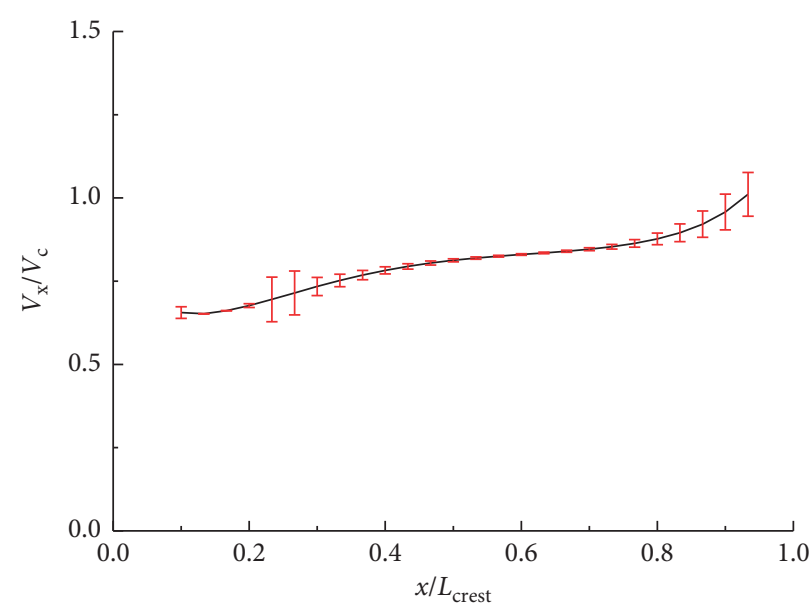

(b)

FIgURE 4: Numerical solutions with error bars by GCI $\left(d_{\mathrm{c}} / h=1.45\right)$ : (a) pressure and $(\mathrm{b})$ velocity.

showing an U-shaped distribution. Conversely, the PIVS pressures change most at $z / w=0$ and little at $z / w=0.5$. In addition, at $z / w=0.25$, the VS and IVS pressures are almost the same, with an S-shaped distribution. PVS and PIVS have similar pressure distribution and magnitude. Therefore, for a given $\theta$ (for either $\mathrm{V}$ or inverted $\mathrm{V}$ ), pool weirs do not impose any significant effect on the pressures at $z / w=0.25$.

3.2. Pressures on Vertical Step Surface. It is noticed that, for all configurations, the pressures acting on the vertical step surfaces decline generally with an increase in water depth. In addition, the pressures of pooled layouts are, regardless of $\theta$, larger than the flat ones. At the selected locations, no negative pressure is found for PVS and PIVS. However, TS shows subpressures in the entire cross section. At $z / w=0$, TS and IVS display a similar level of pressures; the PVS and PIVS pressures are close. At $z / w=0.25$, the VS pressures are almost the same as IVS, which is also true of PVS and PIVS. This implies that, at $z / w=0.25$, inverting the step face angle does not seem to exert any influence on the pressures. At $z / w=0.5$, the TS and VS pressures exhibit a similar distribution pattern; the PIVS pressures are slightly greater than the PVS.

3.3. Extreme Pressures on Step Faces. Let $P_{\min }$ and $P_{\max }$ denote the min. and max. pressures acting upon the step surfaces. Figure 7 compares their values for all the layouts. On the horizontal surfaces, the pressures are positive and increase as flow rate increases. In comparison with the TS layout, VS and IVS with changed step face angles lead to lower $P_{\min }$; PVS and PIVS give roughly three times as large $P_{\min }$ values as TS. For $P_{\max }$, alternation of step face angle and addition of pool weirs give rise to considerably lower $P_{\max }$. VS and IVS exhibit a similar level of $P_{\max }$; PVS and PIVS show an almost same pattern of distribution. In the pooled layouts, the large $P_{\min }$ and $P_{\max }$ values are associated with the larger water depth below the pseudobottom.

On the vertical step surfaces, negative pressures occur only in the configurations without pool weirs; VS and IVS result in slightly higher $P_{\min }$ than TS. For PVS and PIVS, their $P_{\min }$ values are all positive and much higher than other layouts. Moreover, for PVS and PIVS, the difference in $P_{\max }$ is insignificant and their values are almost twice those of TS. VS and IVS lead to almost identical $P_{\max }$ and are moderately larger than TS. A pool weir contains more water that is trapped in the cavities, leading to lager $P_{\max }$ values. Flow separations move from the step edges to the weirs, which contributes to higher $P_{\min }$ values on the vertical step face.

3.4. Pressures on Downstream Bed. The downstream area is of importance to the adjacent hydraulic structures and environment. Therefore, flow pressures on the downstream bed are examined to provide basis for protection measures. Figures $8(\mathrm{a})-8(\mathrm{e})$ show the contours of pressure on the downstream bottom. Figure 8(f) illustrates their max. pressures. It is evident that the TS layout does not lead to any pronounced change in the transverse direction, with extreme pressures occurring along the entire width. The other layouts exhibit a typical 3D pattern. For VS and PVS, their max. pressures occur at the sidewalls, while for IVS and PIVS, they appear on the axial plane. It seems that the locations of extreme pressures are associated with the step face angle, rather than the pool weir. Engineering measures should be undertaken to prevent undesirable scouring at these positions.

As shown in Figure 8(f), for all the layouts, $P_{\max }$ exhibits an almost linear growth as the flow discharge increases, with TS showing significantly lower values than others. For VS and IVS, $P_{\max }$ is slightly larger than that of PVS and PIVS. For the same face angle, the pool weirs reduce $P_{\max }$ on the 


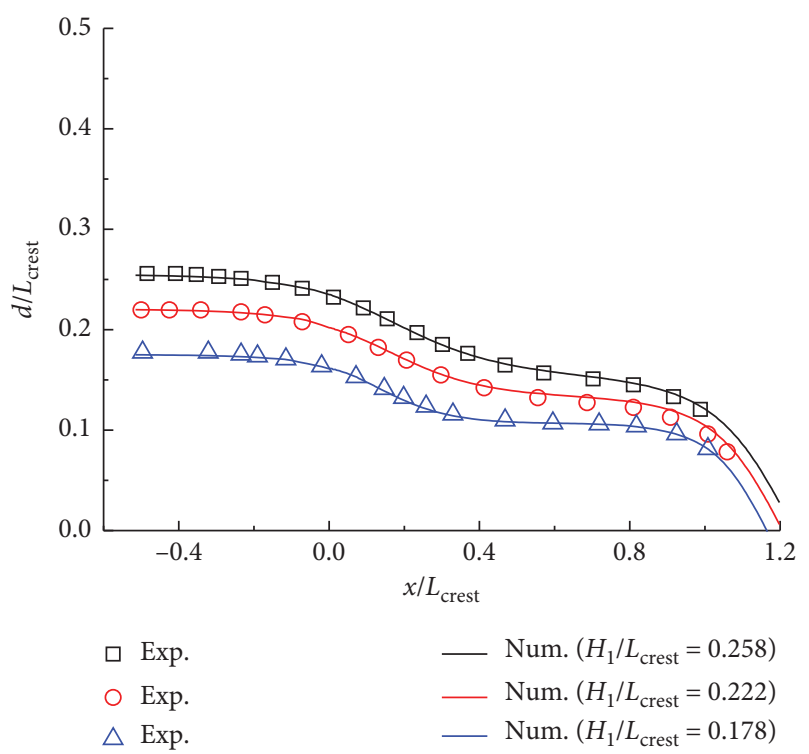

(a)

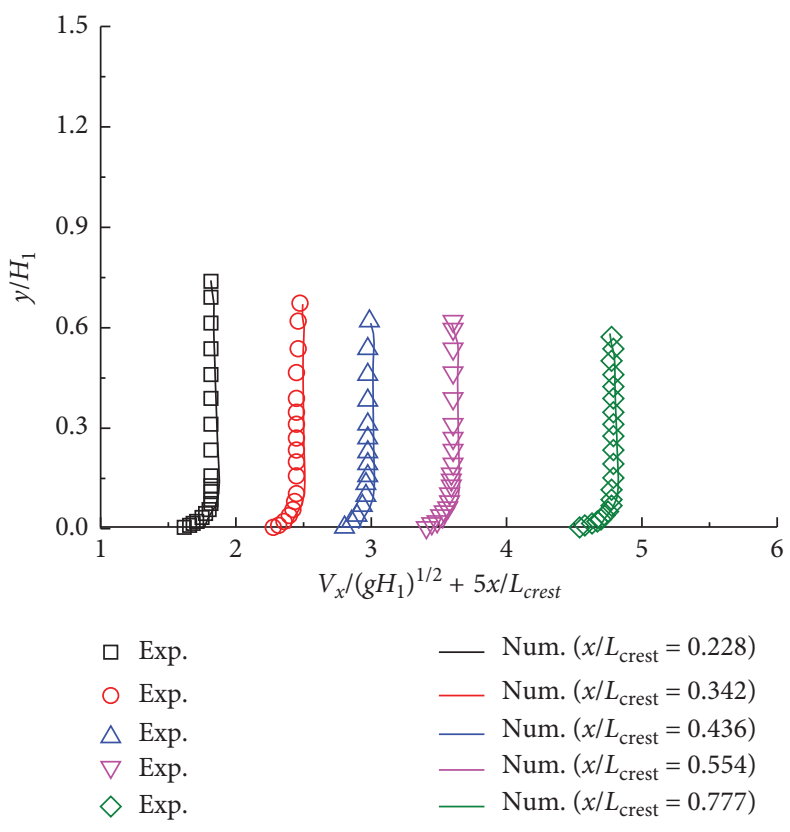

(b)

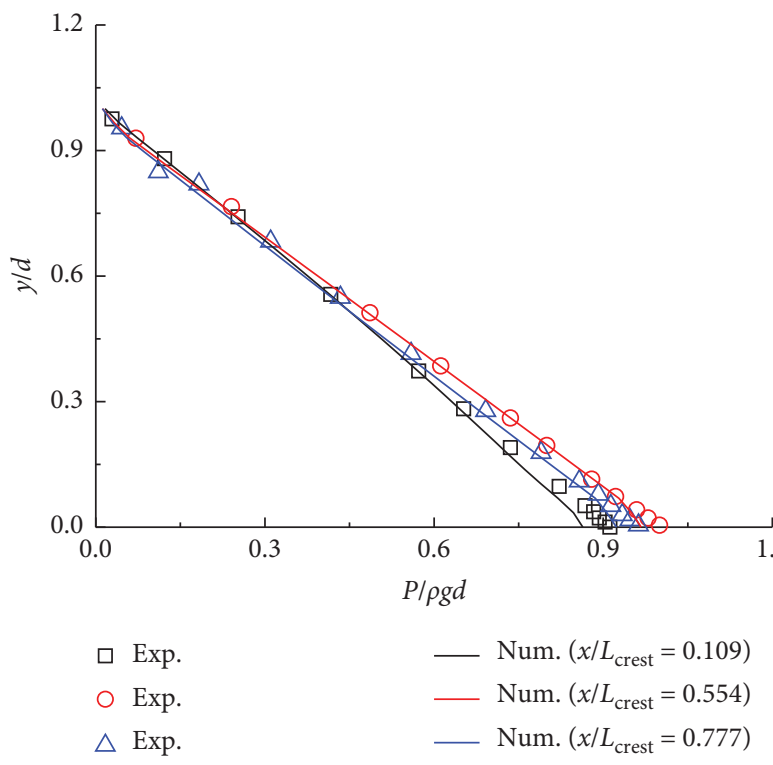

(c)

FiguRe 5: Comparisions between simulations and experiments: (a) free surface, $H_{1} / L_{\text {crest }}=0.224$; (b) velocity profile; (c) pressure distrbution.

bed. However, inverting the step face angle leads to a higher $P_{\max }$.

3.5. Downstream Flow Patterns. The flow patterns in the downstream channel are investigated, shown in Figure 9. As seen from Figures 9(a)-9(e), secondary flows are formed in all the layouts exclusive of TS. In TS, the velocity vectors are approximately parallel; the free surface does not show much change in the transverse direction. For VS and PVS, symmetrical secondary flows occur near the axial planes; the watersurface elevations increase from the sidewalls to the central plane. For IVS and PIVS, secondary flows exist at the sidewalls, where the water depth reaches a maximum. Furthermore, for the same step face angle, larger fluctuations of the water surfaces are seen in the configurations without pool weirs. Therefore, the step face angle affects the locations of secondary flows, while the pool weirs influence the water-surface variations.

Figure 9(f) shows the free surface fluctuation, expressed in terms of $\Delta E l=E l_{\text {max }}-E l_{\text {min }}$, where $E l_{\text {max }}$ and $E l_{\text {min }}$ are the max. and min. water-surface elevation, respectively. As the flow rate increases, $\Delta E l$ becomes larger for all the layouts excluding TS. The $\Delta E l$ values of TS remained unchanged regardless of flow discharge. In addition, for the unpooled 

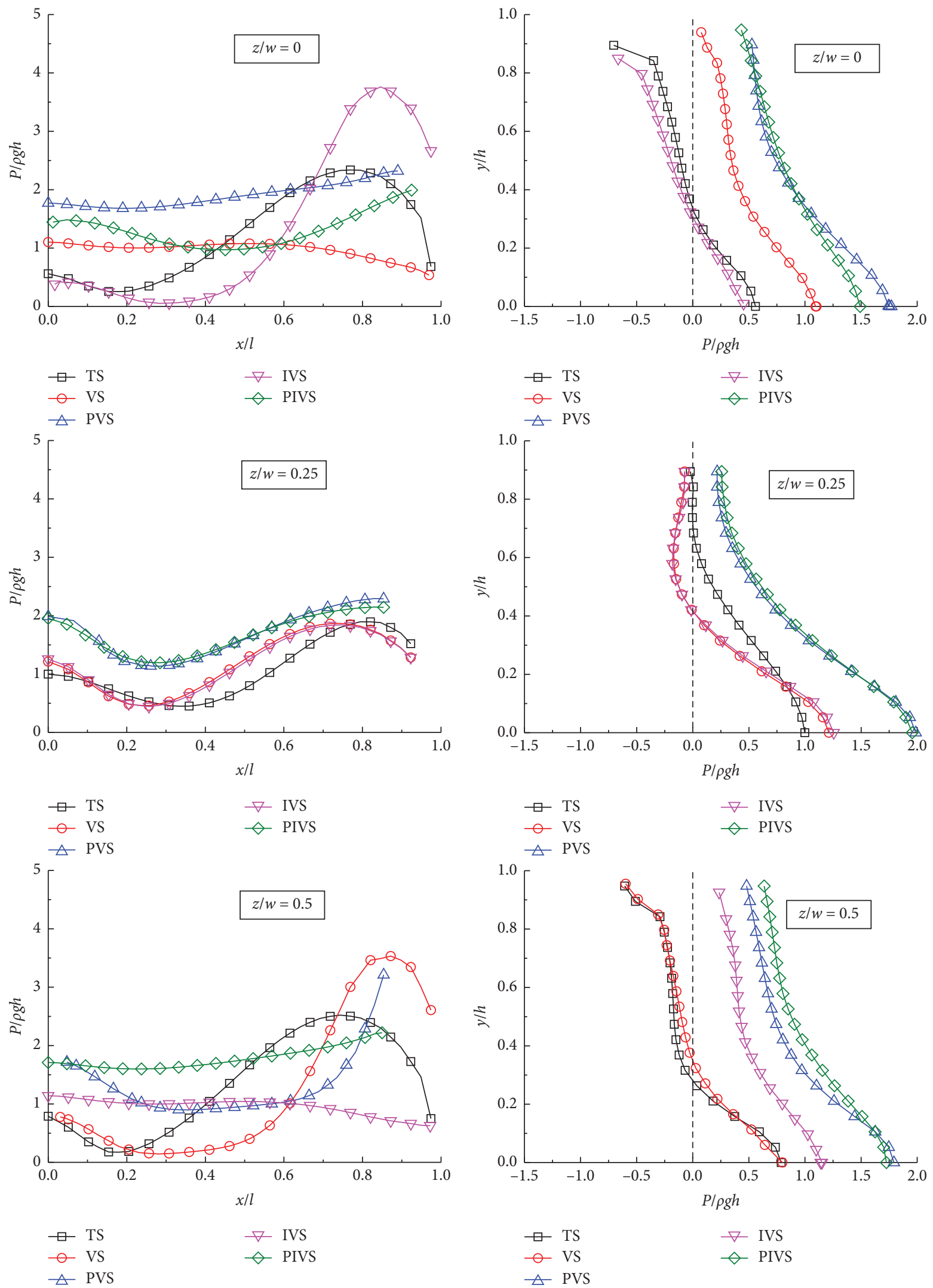

(a)

(b)

Figure 6: Pressures acting on step surfaces (step 10, $d_{c} / h=1.45$ ): (a) horizontal surface; (b) vertical surface. 

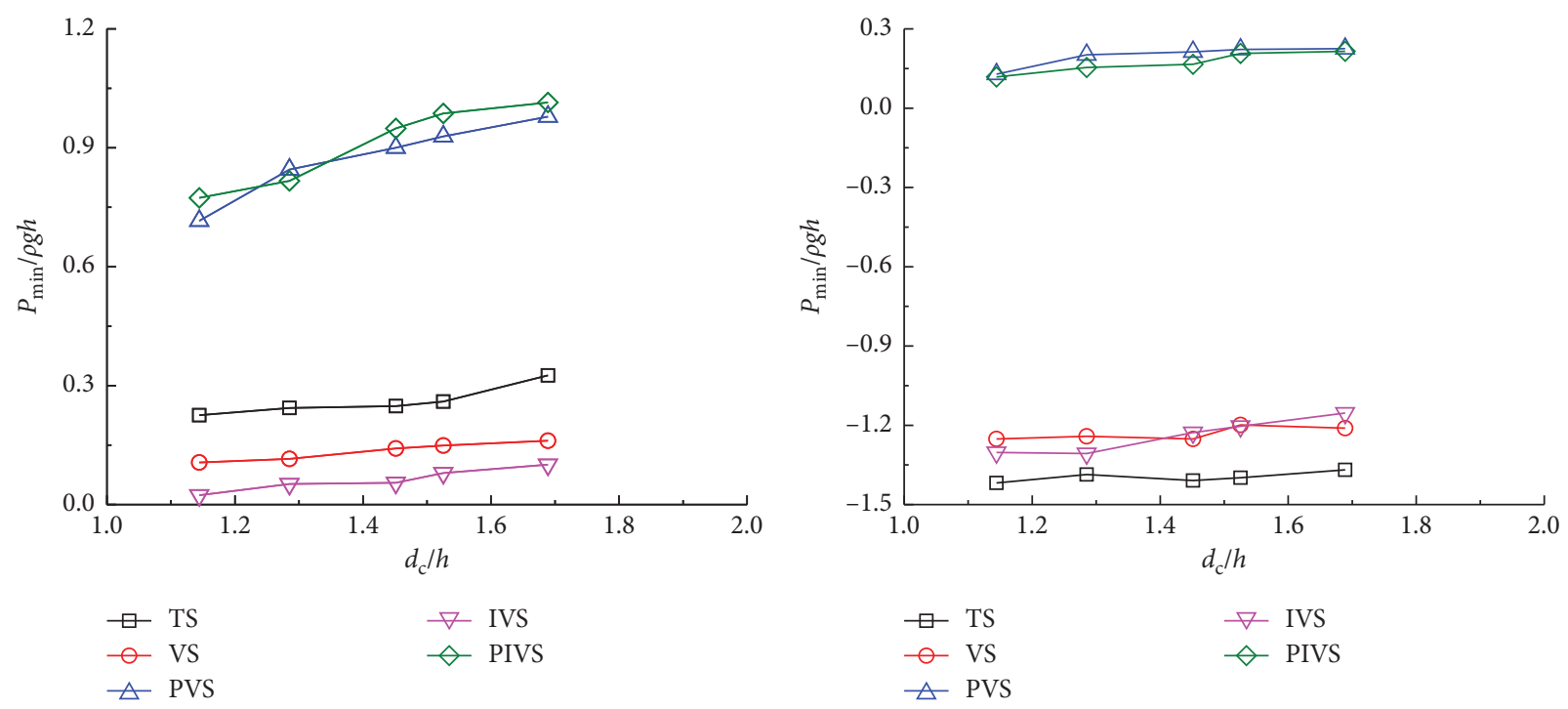

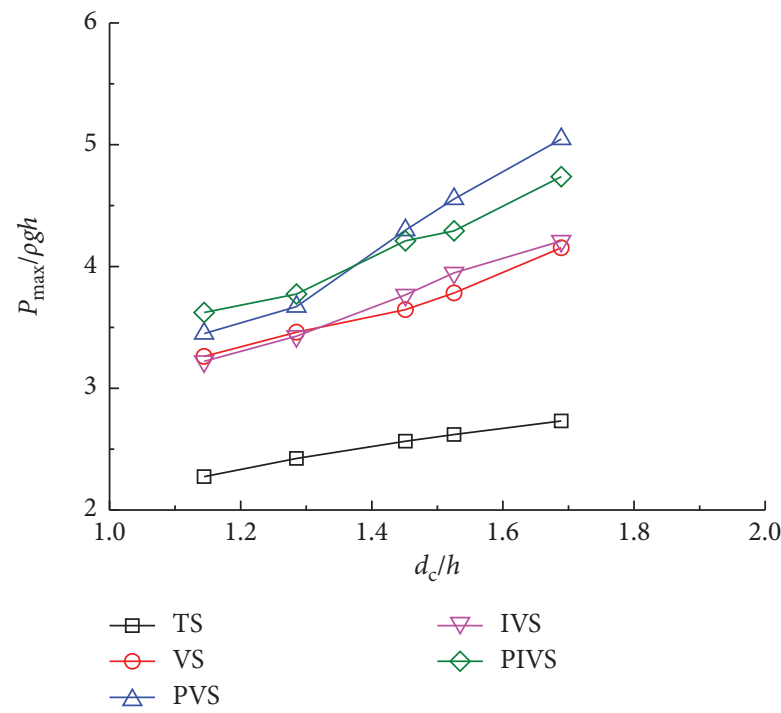

(a)

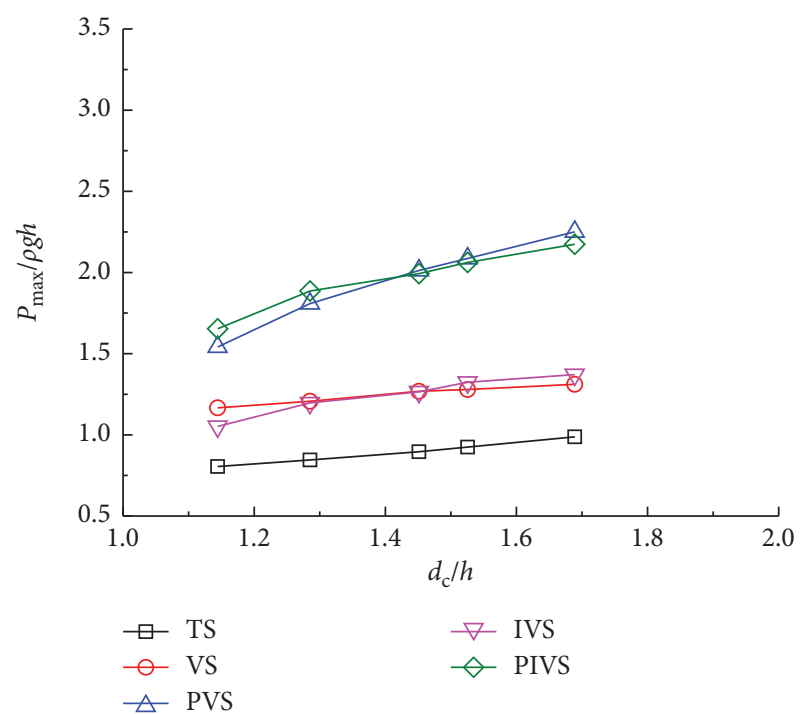

(b)

Figure 7: Min. and max. pressures on step surfaces: (a) horizontal surface and (b) vertical surface.

layouts, the average $\Delta E l$ value is $\sim 70 \%$ higher for the pooled ones. For the inverted $\mathrm{V}$-shaped layouts, it is $\sim 60 \%$ larger than the V-shaped ones.

3.6. Energy Dissipation. On the step surfaces, contours of the turbulent kinetic energy (TKE) are shown in Figure 10(a), providing information about the velocity gradient. The overlaying flow hits the horizontal step faces when flowing downstream and the TKE exhibits extreme values at the downstream end (see the TS plot). For VS, the collision between the flow and step faces occurs near the sidewalls [21], resulting in high velocity gradient in these regions. For PVS, large TKE values are at the pool weirs, which is due to the larger bottom roughness. For the inverted V-shaped layouts, the TKE distributions are similar to the V-shaped ones, however with different locations.
The residual head at the chute end is a key parameter for evaluation of the hydraulic performance of a spillway. The relative energy loss $(\eta)$ is commonly used to quantify its energy dissipation $[11,19,27,35]$ :

$$
\eta=\frac{E_{2}-E_{1}}{E_{2}}
$$

where $E_{1}$ and $E_{2}=$ are the energy heads at the up- and downstream cross sections, respectively, calculated by

$$
\begin{aligned}
& E_{1}=h_{1}+\frac{q_{w}^{2}}{2 g h_{1}^{2}}, \\
& E_{2}=\left(H_{T}+h_{u s}\right)+\frac{q_{w}^{2}}{2 g\left(H_{T}+h_{u s}\right)^{2}},
\end{aligned}
$$



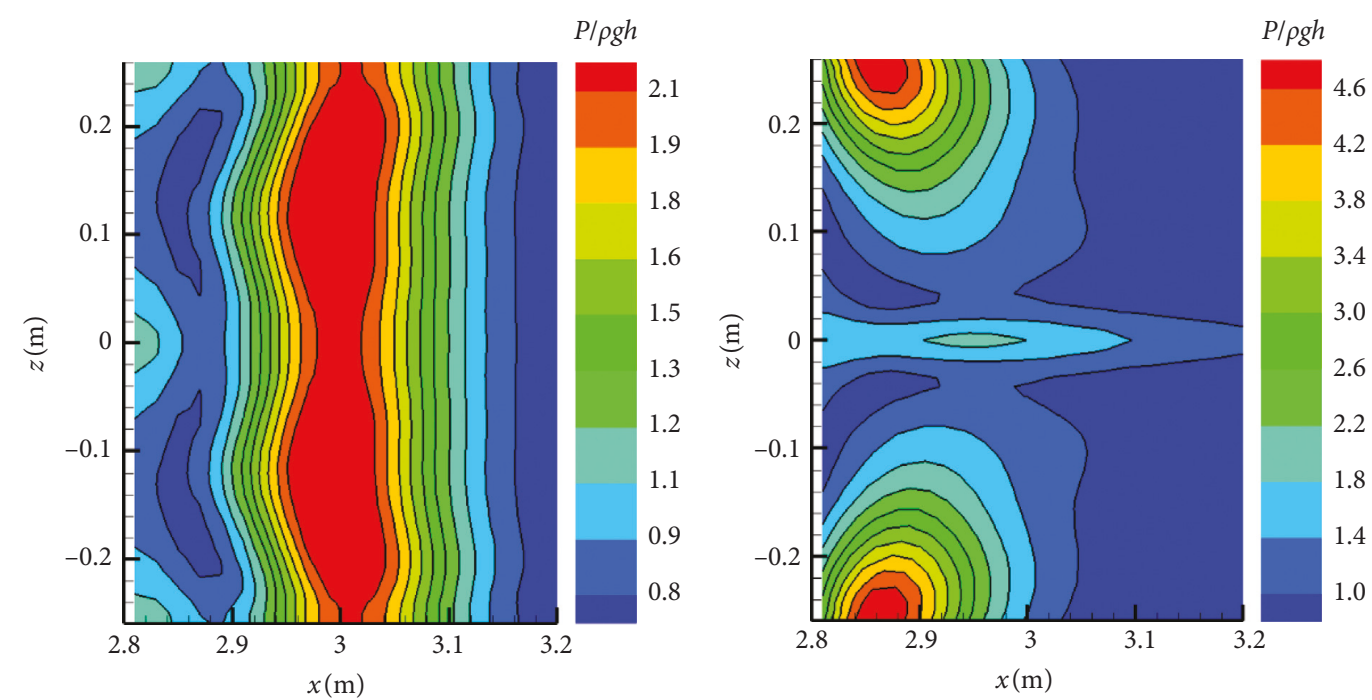

(a)

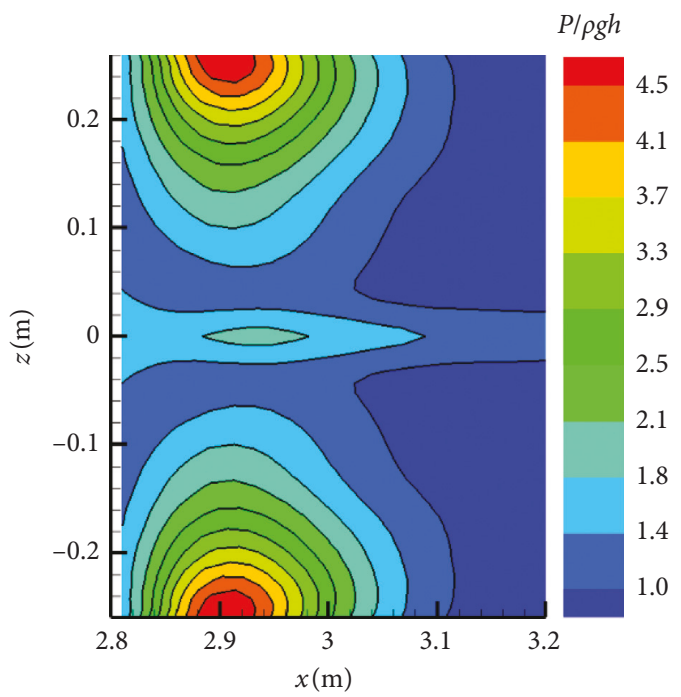

(c) $P / \rho g h$
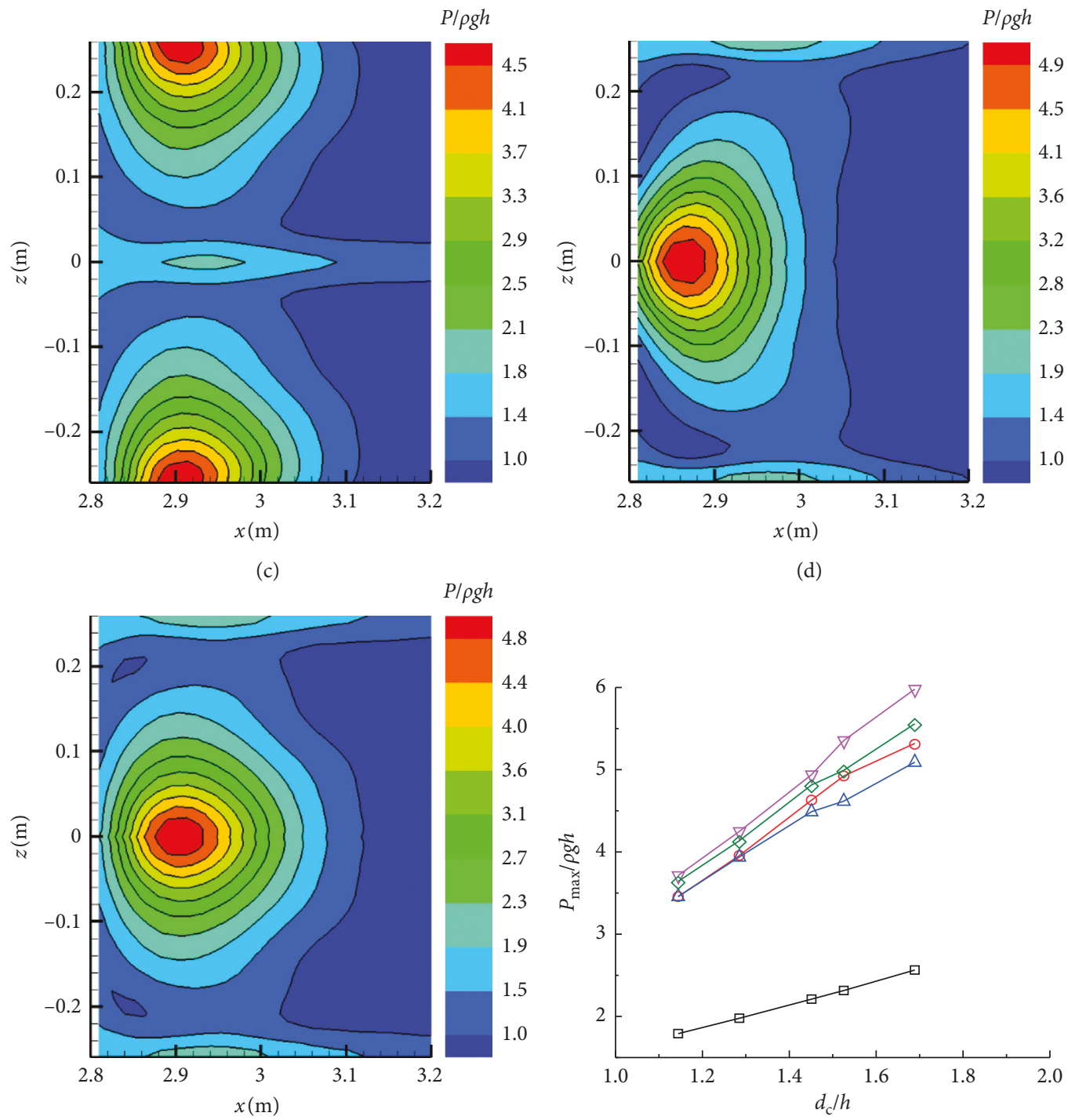

(d)
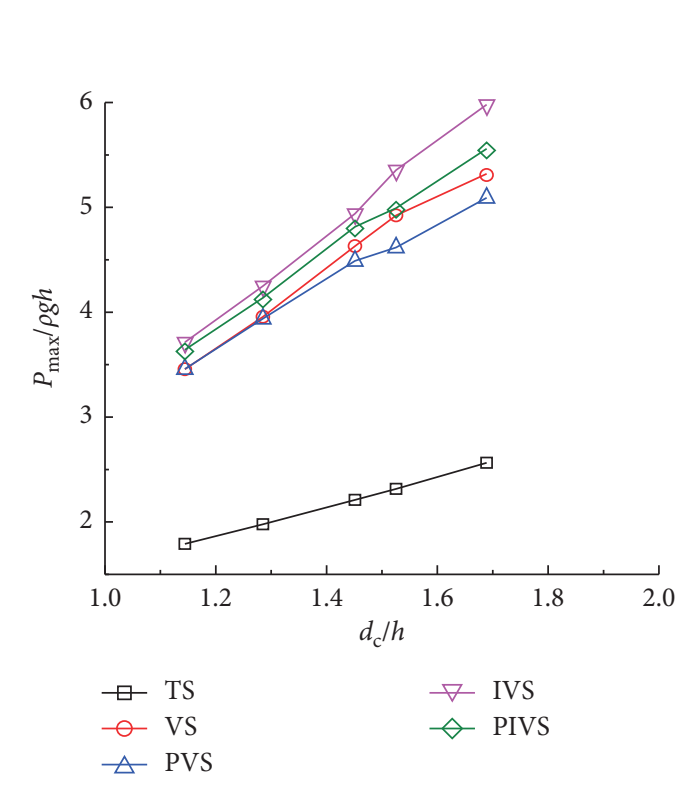

(e)

(f)

Figure 8: Flow pressures acting on the downstream bed $\left(d_{c} / h=1.45\right)$ : (a) TS; (b) VS; (c) PVS; (d) IVS; (e) PIVS; (f) max. pressure. 


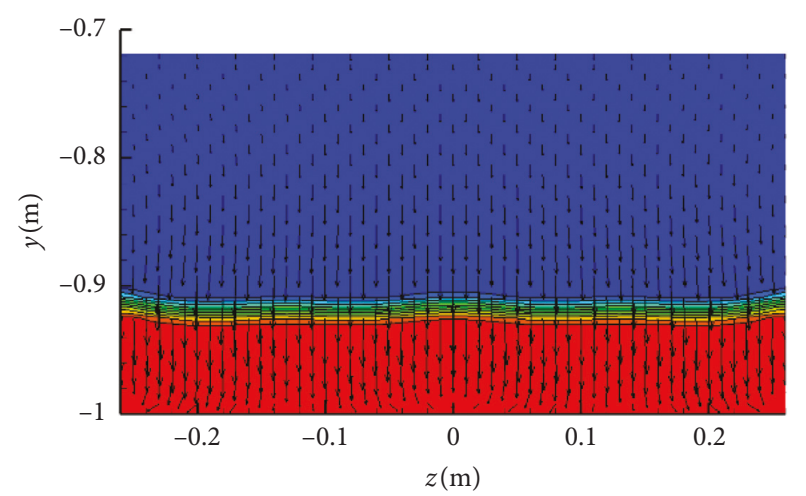

(a)

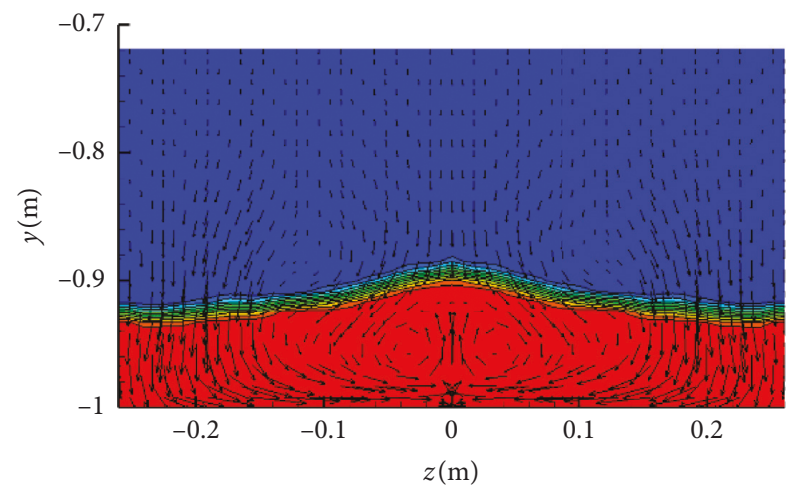

(c)

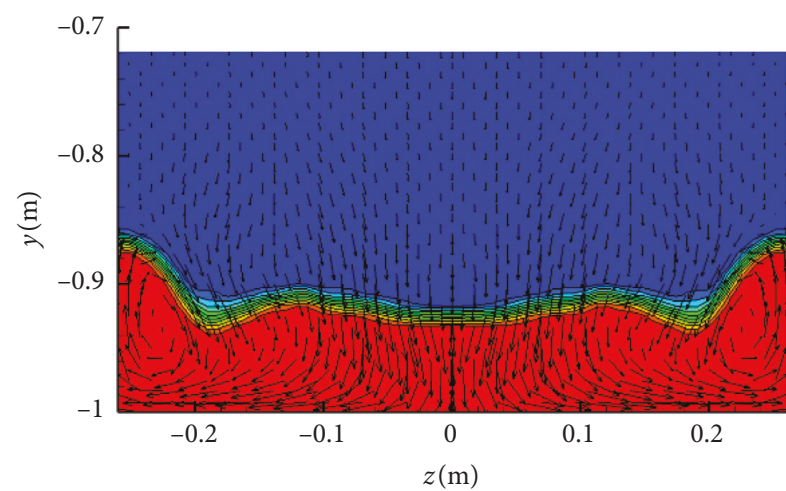

(e)

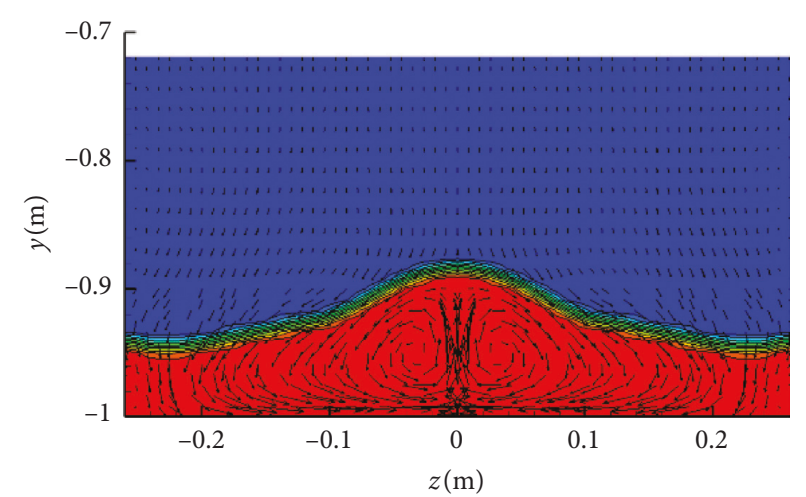

(b)

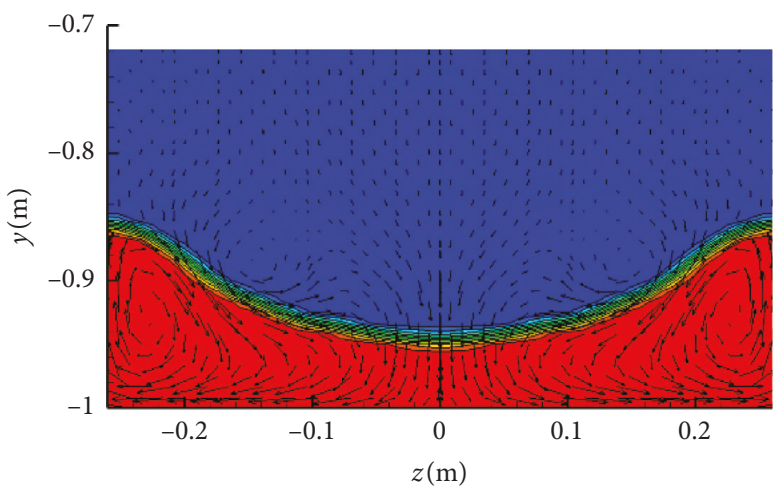

(d)

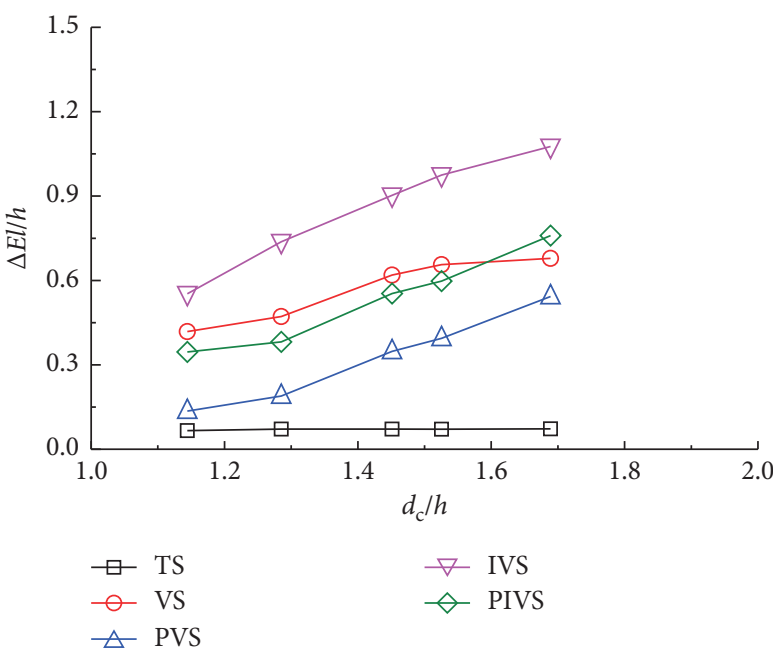

(f)

Figure 9: Flow patterns $\left(x=3 \mathrm{~m}, d_{\mathrm{c}} / h=1.45\right)$ : (a) TS; (b) VS; (c) PVS; (d) IVS; (e) PIVS; (f) free surface fluctuation.

where $h_{1}=$ upstream water depth, $q_{w}=Q / w=$ unit discharge, $H_{T}=$ dam height, and $h_{u s}=$ water head above the spillway crest. Figure 10(b) illustrates the results of the energy dissipation. It is obvious that $\eta$ for all configurations exhibits a downward trend with an increase in flow discharge, which is consistent with the findings in Li et al. [36], Zare and Doering [17], and Chinnarasri and Wongwises [20]. The TS layout leads to the lowest efficiency. In addition, $\eta$ is ranked in the order of $\mathrm{PVS} \approx \mathrm{PIVS}>\mathrm{VS} \approx \mathrm{IVS}>\mathrm{TS}$. For the pooled configurations, their $\eta$ values are, for the same $\theta, \sim 5.4 \%$ larger than those for the flat ones. So all proposed modifications from TS enhance the energy dissipation. The V- and inverted $\mathrm{V}$-shaped ones do not show any significant differences in $\eta$, which is similar to the result of Bai et al. [27]. 


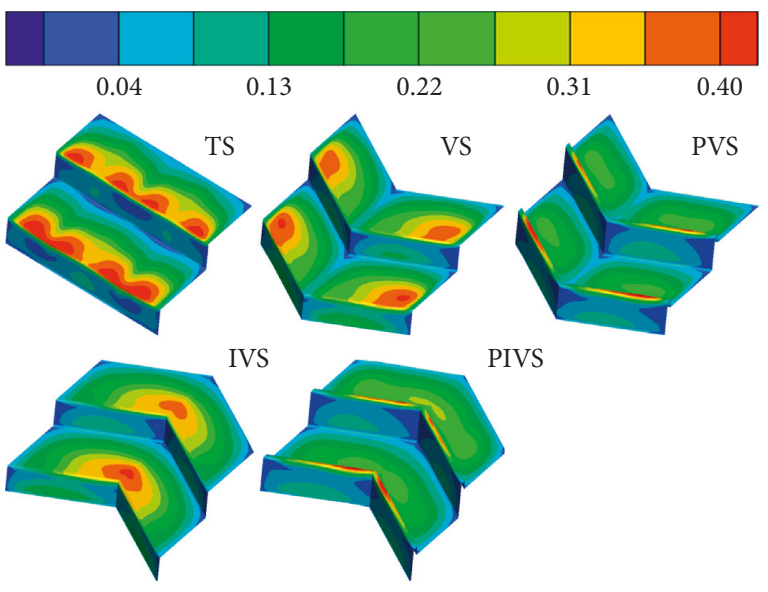

(a)

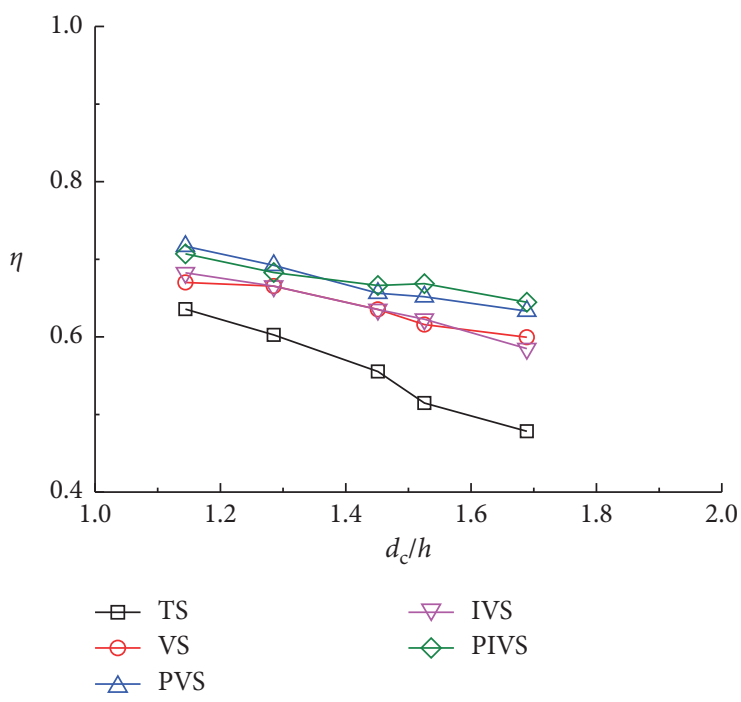

(b)

Figure 10: Energy loss: (a) turbulent kinetic energy $\left(d_{c} / h=1.45\right)$; (b) energy dissipation rate.

\section{Conclusions}

With the increasing use of stepped spillways, step configurations become an issue of concern for an optimized design adapted to varying flow conditions. The study aims to provide insight into the hydraulic features of a stepped spillway with modified step layouts. The modifications refer to distorted step faces and addition of pool weirs. In combination with the $k-\varepsilon$ turbulence model, 3D numerical studies are performed using the two-phase VOF model. The major conclusions include the following:

(i) The pressures on step faces of the V-and inverted $\mathrm{V}$-shaped layouts exhibit a $3 \mathrm{D}$ pattern. For the vertical step surface, cavitation risk is reduced if a pool weir is installed on the horizontal step surface. In addition, the pressures in all the layouts show an upward trend with an increase in flow discharge.

(ii) With the same step face angle, the patterns of pressure distribution on the downstream bottom are similar. However, compared with the pooled ones, the flat stepped layouts result in higher pressures.

(iii) No secondary flow is found in the conventional configuration. If the step face angle is not equal to $180^{\circ}$, it would appear and also lead to differences in water-surface fluctuations.

(iv) As for the energy dissipation rate, the $\mathrm{V}$ - and inverted $\mathrm{V}$-shaped layouts do not lead to any pronounced difference. However, with same step face angle, the flat layouts give $\sim 5.4 \%$ lower values than the pooled ones.

The paper proposes several modified layouts of a stepped spillway, illustrating their effects on the pressure and flow characteristics. Numerical results reveal both their advantages and disadvantages. For instance, negative pressures acting on the vertical step surfaces are reduced with the help of the pool weirs, which is beneficial to the reduction in cavitation risk. However, they also increase the flow pressure loads. Compared with the modified ones, a conventional layout shows favorable flow patterns in the downstream channel; its energy dissipation is however less effective. In addition, owing to the $3 \mathrm{D}$ flow patterns, the modified versions are suitable alternatives for landscape and aeration purposes.

\section{Data Availability}

The data are available from the corresponding author upon request.

\section{Conflicts of Interest}

The authors declare no conflicts of interest regarding the publication of this paper.

\section{Acknowledgments}

The present study is part of research project "Two-phase flow modelling: Evaluations and simulations for safer spillway discharge," which is funded by Swedish Hydropower Centre (SVC). SVC has been established by the Swedish Energy Agency, Energiforsk, and Svenska Kraftnät together with Luleå University of Technology, Royal Institute of Technology, Chalmers University of Technology and Uppsala University. Participating companies and industry associations are Andritz Hydro, Boliden, Fortum Generation, Holmen Energi, Jämtkraft, Karlstads Energi, LKAB, Mälarenergi, Norconsult, Rainpower, Skellefteå Kraft, Sollefteåforsens, Statkraft Sverige, Sweco Energuide, Sweco Infrastructure, Tekniska verken i Linköping, Uniper, Vattenfall R\&D, Vattenfall Vattenkraft, Voith Hydro, WSP Sverige, Zinkgruvan, and $\AA \mathrm{F}$ Industry. The first author 
would like to thank Prof. Anders Ansell at KTH for his supervision and encouragement.

\section{References}

[1] M. E. Emiroglu and A. Baylar, "An investigation of effect of stepped chutes with end sill on aeration performance," Water Quality Research Journal, vol. 38, no. 3, pp. 527-539, 2003.

[2] P. Guenther, S. Felder, and H. Chanson, "Flow aeration, cavity processes and energy dissipation on flat and pooled stepped spillways for embankments," Environmental Fluid Mechanics, vol. 13, no. 5, pp. 503-525, 2013.

[3] H. Chanson, The Hydraulics of Stepped Chutes and Spillways, CRC Press, Boca Raton, FL, USA, 2002.

[4] S. Terrier, M. Pfister, and A. Schleiss, "Comparison of chute aerator effect on stepped and smooth spillways," in Proceedings of the 36th IAHR World Congress 2015, The Hague, The Netherlands, June 2015.

[5] I. Ohtsu, Y. Yasuda, and M. Takahashi, "Flow characteristics of skimming flows in stepped channels," Journal of Hydraulic Engineering, vol. 130, no. 9, pp. 860-869, 2004.

[6] S. Felder, Air-water flow properties on stepped spillways for embankment dams: aeration, energy dissipation and turbulence on uniform, non-uniform and pooled stepped chutes, Ph.D. thesis, School of Civil Engineering, The University of Queensland, Brisbane, Australia, 2013.

[7] R. M. Boes and W. H. Hager, "Hydraulic design of stepped spillways," Journal of Hydraulic Engineering, vol. 129, no. 9, pp. 671-679, 2003.

[8] H. Chanson, "Hydraulic design of stepped spillways and downstream energy dissipators," Dam Engineering, vol. 11, no. 4, pp. 205-242, 2001.

[9] V. Heller, "Scale effects in physical hydraulic engineering models," Journal of Hydraulic Research, vol. 49, no. 3, pp. 293-306, 2011.

[10] H. Chanson, "Comparison of energy dissipation between nappe and skimming flow regimes on stepped chutes," Journal of Hydraulic Research, vol. 32, no. 2, pp. 213-218, 1994.

[11] C. Chinnarasri and S. Wongwises, "Flow patterns and energy dissipation over various stepped chutes," Journal of Irrigation and Drainage Engineering, vol. 132, no. 1, pp. 70-76, 2006.

[12] S. Felder and H. Chanson, "Energy dissipation down a stepped spillway with nonuniform step heights," Journal of Hydraulic Engineering, vol. 137, no. 11, pp. 1543-1548, 2011.

[13] M. Pfister and W. H. Hager, "Self-entrainment of air on stepped spillways," International Journal of Multiphase Flow, vol. 37, no. 2, pp. 99-107, 2011.

[14] S. Felder and H. Chanson, "Energy dissipation, flow resistance and gas-liquid interfacial area in skimming flows on moderate-slope stepped spillways," Environmental Fluid Mechanics, vol. 9, no. 4, pp. 427-441, 2009.

[15] D. B. Bung, "Non-intrusive detection of air-water surface roughness in self-aerated chute flows," Journal of Hydraulic Research, vol. 51, no. 3, pp. 322-329, 2013.

[16] J. Matos, Y. Yasuda, and H. Chanson, "Interaction between free-surface aeration and cavity recirculation in skimming flows down stepped chutes," in Proceedings of the 29th IAHR Congress 2001, vol. 2, pp. 611-617, Beijing, China, September 2001.

[17] H. K. Zare and J. C. Doering, "Energy dissipation and flow characteristics of baffles and sills on stepped spillways," Journal of Hydraulic Research, vol. 50, no. 2, pp. 192-199, 2012.
[18] M. A. Kökpinar, "Flow over a stepped chute with and without macro-roughness elements," Canadian Journal of Civil Engineering, vol. 31, no. 5, pp. 880-891, 2004.

[19] H. K. Zare and J. C. Doering, "Effect of rounding edges of stepped spillways on the flow characteristics," Canadian Journal of Civil Engineering, vol. 39, no. 2, pp. 140-153, 2012.

[20] C. Chinnarasri and S. Wongwises, "Flow regimes and energy loss on chutes with upward inclined steps," Canadian Journal of Civil Engineering, vol. 31, no. 5, pp. 870-879, 2004.

[21] Z. L. Bai, Y. Peng, and J. M. Zhang, "Three-dimensional turbulence simulation of flow in a V-shaped stepped spillway," Journal of Hydraulic Engineering, vol. 143, no. 9, Article ID 06017011, 2017.

[22] S. Felder and H. Chanson, "Free-surface profiles, velocity and pressure distributions on a broad-crested weir: a physical study," Journal of Irrigation and Drainage Engineering, vol. 138, no. 12, pp. 1068-1074, 2012.

[23] Y. Peng, J. Zhang, and J. Meng, "Second-order force scheme for lattice Boltzmann model of shallow water flows," Journal of Hydraulic Research, vol. 55, no. 4, pp. 592-597, 2017.

[24] Y. Peng, J. M. Zhang, and J. G. Zhou, "Lattice Boltzmann model using two relaxation times for shallow-water equations," Journal of Hydraulic Engineering, vol. 142, no. 2, Article ID 06015017, 2015.

[25] Y. Peng, J. G. Zhou, and R. Burrows, “Modeling free-surface flow in rectangular shallow basins by using lattice Boltzmann method," Journal of Hydraulic Engineering, vol. 137, no. 12, pp. 1680-1685, 2011.

[26] Y. Peng, J. G. Zhou, and R. Burrows, "Modelling solute transport in shallow water with the lattice Boltzmann method," Computers \& Fluids, vol. 50, no. 1, pp. 181-188, 2011.

[27] Z. Bai, Y. Wang, and J. Zhang, "Pressure distributions of stepped spillways with different horizontal face angles," Proceedings of the Institution of Civil Engineers-Water Management, vol. 171, no. 6, pp. 299-310, 2017.

[28] Z. Bai and J. Zhang, "Comparison of different turbulence models for numerical simulation of pressure distribution in V-shaped stepped spillway," Mathematical Problems in Engineering, vol. 2017, Article ID 3537026, 9 pages, 2017.

[29] Q. Chen, G. Dai, and H. Liu, "Volume of fluid model for turbulence numerical simulation of stepped spillway overflow," Journal of Hydraulic Engineering, vol. 128, no. 7, pp. 683-688, 2002.

[30] B. E. Launder and D. B. Spalding, Mathematical Models of Turbulence (No. BOOK), Academic Press, Cambridge, MA, USA, 1972.

[31] P. J. Roache, "Perspective: a method for uniform reporting of grid refinement studies," Journal of Fluids Engineering, vol. 116, no. 3, pp. 405-413, 1994.

[32] P. J. Roache, "Quantification of uncertainty in computational fluid dynamics," Annual Review of Fluid Mechanics, vol. 29, no. 1, pp. 123-160, 1997.

[33] P. J. Roache, "Verification of codes and calculations," AIAA Journal, vol. 36, no. 5, pp. 696-702, 1998.

[34] I. B. Celik, U. Ghia, P. J. Roache, and C. Freitas, "Procedure for estimation and reporting of uncertainty due to discretization in CFD applications," Journal of Fluids Engineering, vol. 130, no. 7, Article ID 078001, 2008.

[35] S. Li and J. Zhang, "Numerical investigation on the hydraulic properties of the skimming flow over pooled stepped spillway," Water, vol. 10, no. 10, p. 1478, 2018.

[36] S. Li, J. Zhang, and W. Xu, "Numerical investigation of air-water flow properties over steep flat and pooled stepped spillways," Journal of Hydraulic Research, vol. 56, no. 1, pp. 1-14, 2018. 


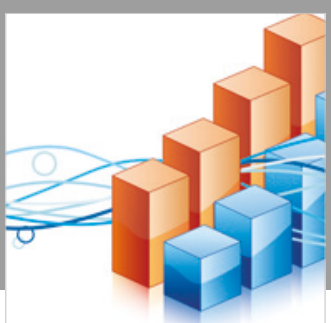

Advances in

Operations Research

\section{-n-m}
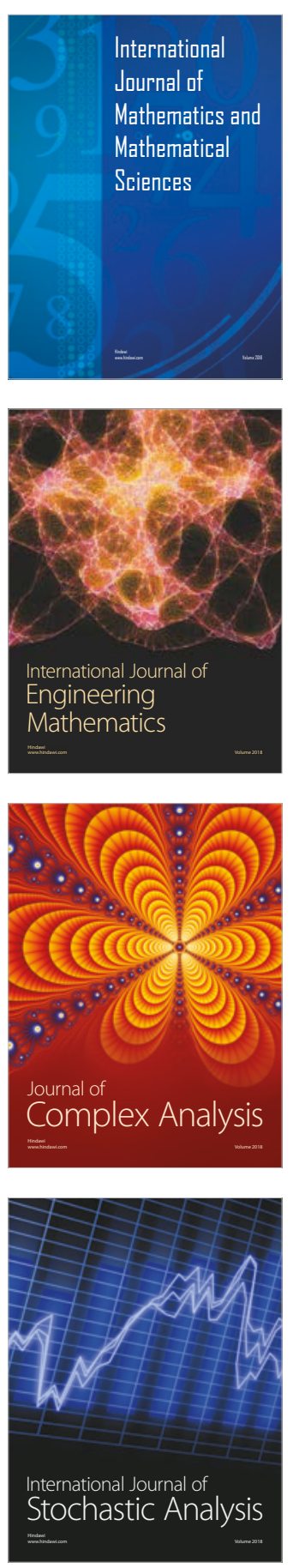
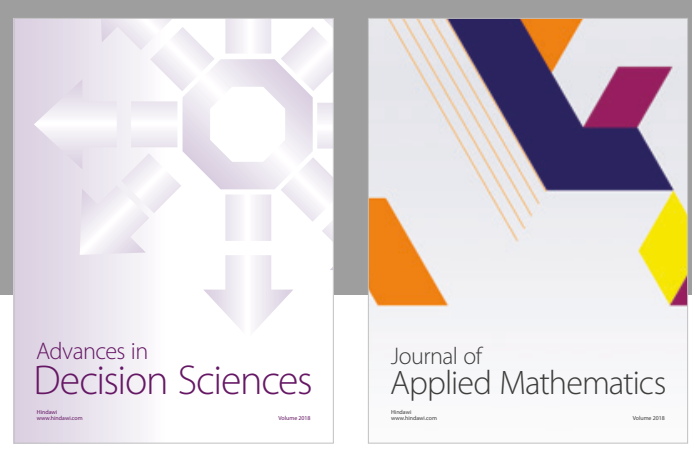

Journal of

Applied Mathematics
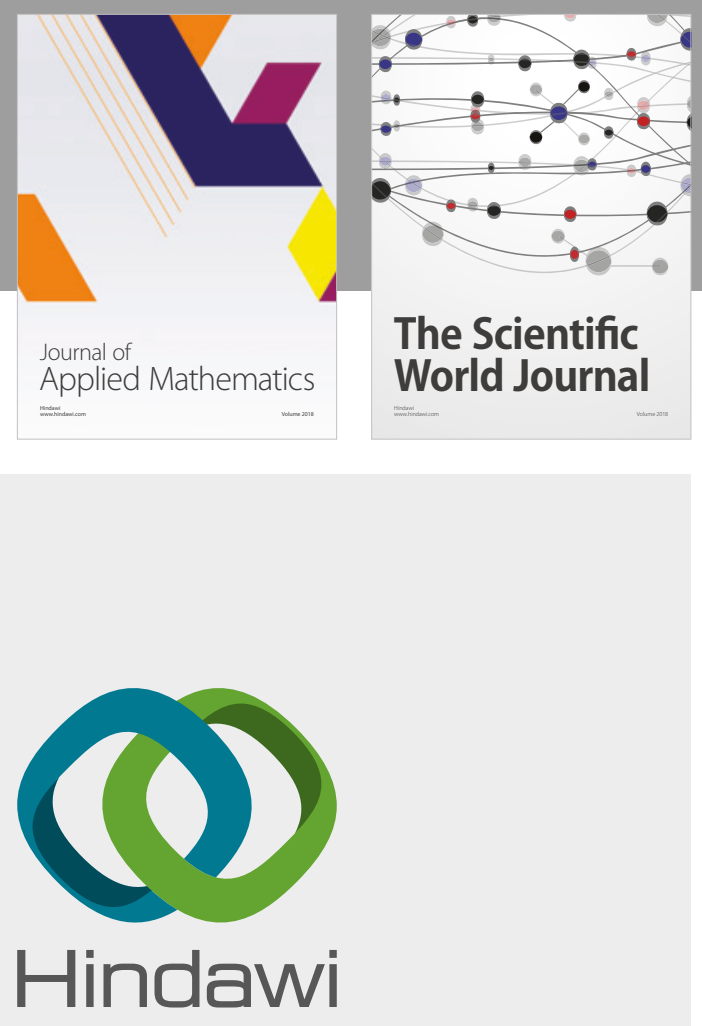

Submit your manuscripts at

www.hindawi.com

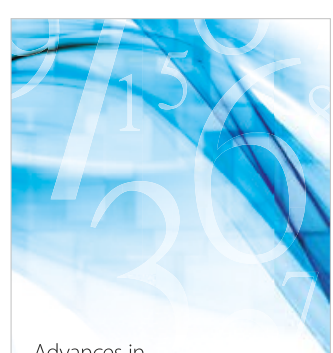

Advances in
Numerical Analysis
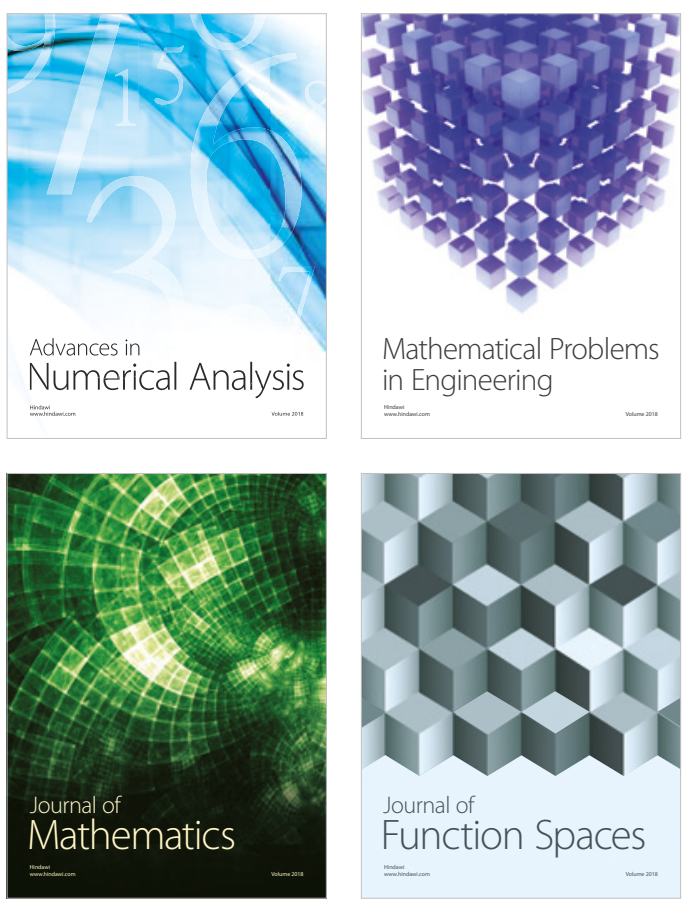

Mathematical Problems in Engineering

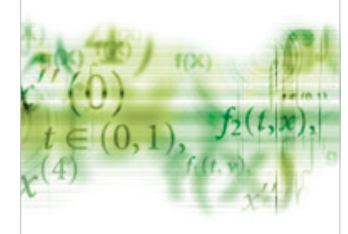

International Journal of

Differential Equations

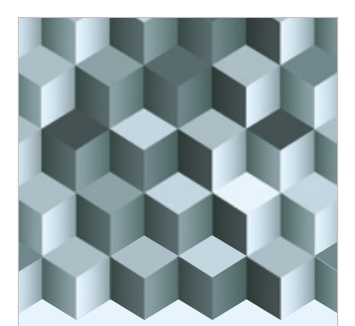

Journal of

Function Spaces

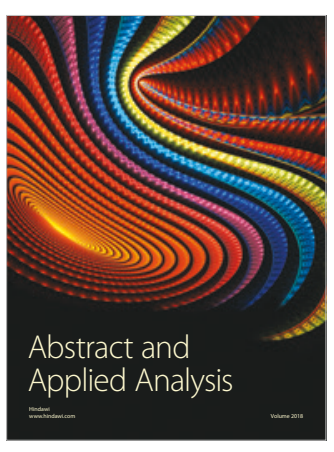

The Scientific

World Journal

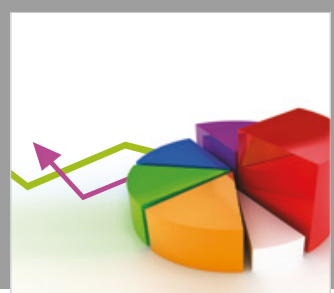

Journal of

Probability and Statistics
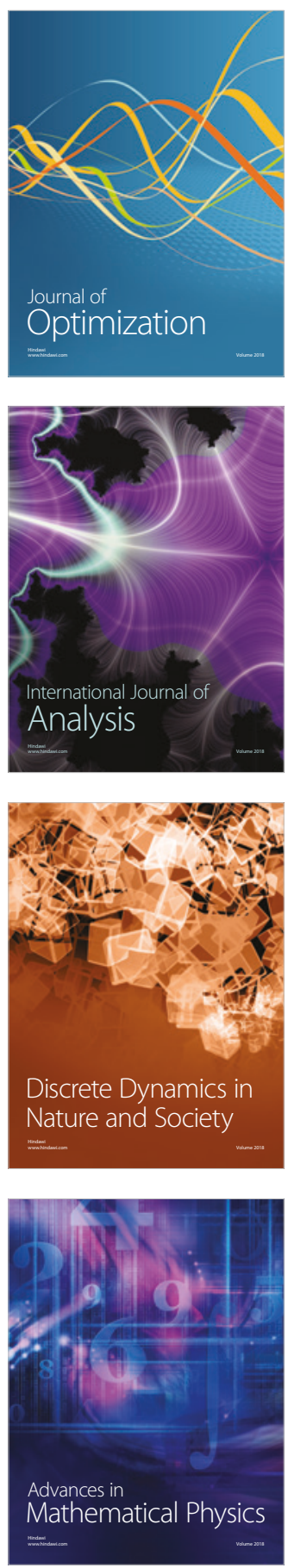